\title{
More than meets the eye
}

\author{
Christoph Haller, MD, and John Coles, MD

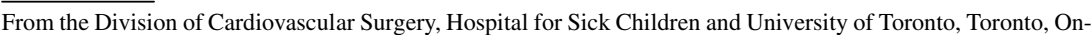 \\ tario, Canada. \\ Disclosures: Authors have nothing to disclose with regard to commercial support. \\ Received for publication Oct 5, 2016; revisions received Oct 5, 2016; accepted for publication Oct 5, 2016; \\ available ahead of print Dec 10, 2016. \\ Address for reprints: John Coles, MD, 555 University Ave, M5G 1X8 Toronto, Ontario, Canada (E-mail: john. \\ coles@sickkids.ca). \\ J Thorac Cardiovasc Surg 2017;153:428-9 \\ $0022-5223 / \$ 36.00$ \\ Crown Copyright $\odot 2016$ Published by Elsevier Inc. on behalf of The American Association for Thoracic Surgery \\ http://dx.doi.org/10.1016/j.jtcvs.2016.10.009
}

Repair of coarctation of the aorta in general can be considered a success story. The results are excellent and repair can be performed with freedom from major complications in $93.5 \%$ of patients. ${ }^{1}$ Nevertheless, survival remains worse when compared with a matched population and lifelong follow-up is mandatory. ${ }^{2}$

With the focus of congenital cardiac surgery shifting from the reduction of mortality per se toward improvement of long-term outcome, the term "successful repair" may have to be redefined for many congenital defects. Bruse and colleagues ${ }^{3}$ challenge this in patients with coarctation of the aorta by analysis of the geometry more than 20 years after the initial repair. Three-dimensional magnetic resonance imaging data were used to construct the mean aortic shape of the study population. Deviations from this mean aortic shape were calculated and their influence on ventricular function, ventricular mass, and end diastolic volume assessed.

Pattern recognition, or in other words, condensing subjective visual interpretation into the objectivity of measurable parameters, first and foremost depends on the correct definition of success. Current routinely used techniques to assess patients after coarctation repair leave important aspects unobserved. They neither respect the complexity of the 3-dimensional shape in total, nor the biomechanical properties or complex blood flow patterns. Gradients measured by ultrasound are affected by ventricular function, anatomical narrowing may overor underestimate its physiologic influence, and turbulence does not reflect altered mechanical wall characteristics. Therefore, detailed analysis of the aortic arch shape definitely adds depth to the interpretation of postoperative imaging.

A closer look at the results reveals that although there was an association between lower left ventricular ejection fraction, higher indexed left ventricular mass, or higher indexed end diastolic left ventricular volume and a Gothic aortic arch shape, all these parameters were within normal limits 20.6 years after the repair. Does this suffice to change the operative technique? Should we therefore tion of success.

\section{References} 2014;97:1838-49.

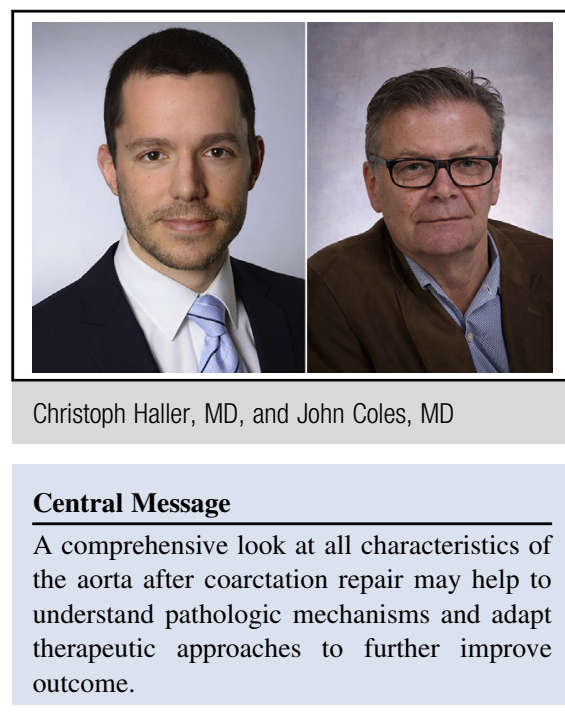

See Article page 418

strive for a Romanesque shape? Rather not. Surgical techniques may take the resulting aortic shape into consideration, such as the preservation of the lesser curvature of the aortic arch described by Deleon and colleagues, ${ }^{4}$ but their use is limited to suitable anatomies. It is unlikely that more complex reconstructions with the sole purpose of achieving a Romanesque form would yield better outcome. And other aspects affecting ventricular function have not been considered. Bioelastic properties of the aorta after coarctation repair are impaired and this in turn causes left ventricular diastolic dysfunction. ${ }^{5}$ Different types of repair and the presence or absence of a bicuspid aortic valve influence ventricular function as well. Furthermore, an interpretation of the results with regard to the preoperative shape of the aorta would help to construe the influence of the shape itself.

Nevertheless, this must not be interpreted as harsh criticism. The analysis of magnetic resonance imaging gives us new insights into the postrepair anatomy of coarctation patients and objectifies our already existing interpretation. Once we succeed in combining aortic shape, flow, and wall properties, we may indeed be able to revise our defini-

1. Mavroudis C, Mavroudis CD, Jacobs JP, Siegel A, Pasquali Sk, Hill KD, et al. Procedure-based complications to guide informed consent: analysis of Society of Thoracic Surgeons Congenital Heart Surgery database. Ann Thorac Surg. 
2. Brown ML, Burkhart HM, Connolly HM, Dearani JA, Cetta F, Li Z, et al. Coarctation of the aorta: lifelong surveillance is mandatory following surgical repair. J Am Coll Cardiol. 2013;62:1020-5.

3. Bruse JL, Khushnood A, McLeod K, Biglino G, Sermesant M, Pennec X, et al. How successful is successful? Aortic arch shape following successful aortic coarctation repair correlates with left ventricular function. J Thorac Cardiovasc Surg. 2017;153:418-27.
4. Deleon SY, Desikacharlu A, Dorotan JG, Lane J, Cvetkovic DR, Myers JL. Modified extended end-to-end repair of coarctation in neonates and infants. Pediatr Cardiol. 2007;28:355-7.

5. Voges I, Kees J, Jerosch-Herold M, Gottschalk H, Trentmann J, Hart C, et al. Aortic stiffening and its impact on left atrial volumes and function in patients after successful coarctation repair: a multiparametric cardiovascular magnetic resonance study. J Cardiovasc Magn Reson. 2016;18:56. 